Sharif University of Technology
Scientia Iranica
SCIENTIA
I RAN I C A
http://scientiairanica.sharif.edu

\title{
Mode choice and number of non-work stops during the commute: Application of a copula-based joint model
}

\author{
A. Rasaizadi* and M. Kermanshah \\ Department of Civil Engineering, Sharif University of Technology, Tehran, P.O. Box 9313-11155, Iran.
}

Received 28 November 2015; received in revised form 30 September 2016; accepted 12 November 2016

\author{
KEYWORDS \\ Joint model; \\ Copula; \\ Mode choice; \\ Number of stops; \\ Trip chain; \\ Work trips.
}

\begin{abstract}
Commute mode choice and number of non-work stops during the commute are joint decisions interacting with each other. If an individual chooses a vehicle for the commute, regarding vehicle's restrictions, there could be some stops. On the other hand, if an individual needs to have some stops, a vehicle can be selected for the commute regarding the number of stops. In this study, to consider the interaction between these decisions, we employed a copula-based joint modeling framework. The data used in this study are drawn from origin-destination travels data of Shiraz-Iran conducted in 1997. The commuting mode choice modeling is undertaken using a multinomial logit model, and the number of non-work stops is modeled using an ordered response formulation. To capture the interaction between these decisions, several copula functions have been used. Results confirm that the mode and number of non-work stop choices are interrelated choices by estimating the commonly observed factors and dependence parameters with high statistical significance. By determining common effective factors, we can analyze the current situation in the community. Therefore, we can use the results so as to forecast future travel demand and set some policies, leading to the promotion of trip chaining.
\end{abstract}

(C) 2018 Sharif University of Technology. All rights reserved.

\section{Introduction}

The continual growth of urban travels, in particular, traveling with the private vehicle, is one of the major reasons causing urban traffic congestion and related problems such as noise and environmental pollutions, energy waste, and safety decline [1]. As the quality of human life improves, more comfort and convenience come along; in terms of a travel behavior scope, this leads to the increasing use of personal vehicle. Under such conditions, changing transportation infrastruc-

\footnotetext{
*. Corresponding author. Fax: +982166014828 E-mail addresses: Arash_rasa@yahoo.com (A. Rasaizadi) Mkerman@sharif.edu (M. Kermanshah).
}

tures is necessary to service the vehicles [1]. The high cost of constructions and operations necessitates a planner to find better options. There are policies and planning along with the development of transportation infrastructures that could meet the future requirements.

To solve traffic congestion, we must determine factors causing this problem. Work and educational trips constitute a major part of traffic congestion in the morning and evening during peak hours. The home-to-work-trip traffic congestion occurs during the morning peak hours, and the work-to-home-commute traffic congestion occurs during the evening peak hours. Work and educational trips constitute a major share of people's trip. These trips are considered as mandatory ones that, principally, could be not eliminated. For mandatory trips, we can induce conditions that 
facilitate traffic congestion reduction, e.g. promoting planned trip chain and improving public transportation efficiency.

Usually, when people face traffic congestion, they look for greater use of their travel. For example, instead of two separated trips to work and markets, they add stops in their work trip and do the shopping while cancelling their shopping trip. This idea is the basis for the formation of the trip chaining. The trip chain is a set of trips that people with the intention of making some stops would obtain their secondary goals in their main trip. In the rest of this paper, work and educational trips are considered as the work trip. This study examines work trip chains that have at least one non-work stop.

According to the above points, having more nonwork stops during the commute and using public transport can reduce traffic congestion, significantly. Achieving several goals during the commute needs spending more time, and using public transport adds to the time spent [2]. Therefore, it can be expected that private vehicle utilization is more favorable and likely in such conditions [2]. This point indicates the complexity of the planning.

The rest of this paper is structured as follows. The next section provides a literature review. Section 3 discusses the methodology. Section 4 describes the data source. Section 5 reports results. Conclusions are reported in the final section.

\section{Literature review}

Some earlier studies ignore the interaction between the commute mode and number of non-work stops [35]. Several studies are focused on the analysis of the number of stops without considering the effect of the commute mode [3,4]; on the contrary, a large number of studies are focused on the commute mode choice with no regards to the effect of the number of stops [5].

Some others have attempted to establish a tenuous link between stop-making and mode choice using one variable as an independent variable to describe another variable [6-8]. For example, Bhat and Sardesai [7] utilized the number of stops and travel time reliability as independent variables in the commute mode choice model. As an example, Strathman et al. [8] used trip characteristic, such as a commute mode, in the number of stops model. Some studies considered the interaction between commute mode choice and the number of stops and used joint modeling formulation; however, commute stops model is represented as a binary choice (no commute stops and one or more stops) $[9,10]$.

Bhat [2] used an econometric structure for joint modeling of commute mode choice and the number of non-work stops where the number of stops can obtain any positive and integer values. The number of stops is modeled using an ordered logit model, while the commute mode choice is modeled using a multi-nominal logit model. In this study, the key point is finding the joint probability function. In other words, for each individual, we must determine the joint probability of choosing the combination of each mode and each number of stops. According to the observation, the likelihood function is formed and maximized. Bhat formed a bivariate joint distribution as follows [2]:

- Error terms of commute mode choice follow the Gumbel distribution. Its cumulative distribution is calculated. By using normal inverse cumulative distribution, Gumbel distribution is converted into a normal distribution;

- Error terms of the number of stops follow the normal distribution;

- By using the bivariate normal distribution, joint bivariate distribution of error terms and joint probability function are computed.

These methods can consider the interaction between decisions, but restricting the relationship to one form is inappropriate. There are other functions that may be more appropriate to describing this correlation. Such functions are known as copulas. The copula is a function that generates a stochastic dependence relationship among random variables with pre-specified marginal distributions [1].

Finally, Bhat et al. [1] used copula in joint modeling of the commute mode choice and the number of stops during the commute. The data used in this study are drawn from the time-use multi-purpose survey conducted between 2002 to 2003 in a greater Turin metropolitan area of Italy. Mode choice model includes four choices: drive alone, shared ride, active transport, and public transport. the Number of stops includes $0,1,2$, and more than 2 stops.

Frank and Gaussian copulas are used for joint modeling. The best model is obtained by the Gaussian copula that has log-likelihood equal to -1652.39 . Results confirm the interaction between the two decisions [1].

The existence of some common observed and unobserved factors between these decisions indicates that these decisions are not separated and are not given priority. Some previous studies have considered the priority of these decisions. By using copula-based joint model, this study removed this priority. This paper used this methodology for joint modeling of mode choice and the number of non-work stops for the Iranian community using travel data of shiraz. Determining elasticity for dummy and ordered variable is considered as another novelty of this paper. 


\section{Methodology}

This paper employed a copula-based joint model to recognize the factors with simultaneous effects on mode choice and the number of non-work stops. Some visible factors have common effects on mode choice and number of non-work stops. These factors are considered as commonly observed factors. Therefore, by obtaining knowledge about common factors, we can set some policies to increase the probability of choosing public transport and have more non-work stops during the commute facilitating traffic congestion reduction. Further, there are some common unobserved factors between the two choices whose effects are undetectable by us in a systematic way. Therefore, the current paper employed some copula functions to consider the correlation between unobserved factors of the two models.

The commute mode choice is modeled using multinomial logit formulation. Assume that error terms of utility functions are identically and independently Gumbel distribution. The ordered-logit formulation is adopted for the number of non-work stops model. Assume that error terms of propensity function have a standard logistic distribution. Assumptions have been made on the basis of earlier studies' assumptions [1]. In this study, FGM, AMH, Frank, Gaussian, Gumbel, and Product copulas have been used to obtain a better fitted model. The copula with the greatest loglikelihood and dependence parameters in an acceptable range is the best copula.

\subsection{Model structure}

The commute mode choice was modeled using a multinomial logit model. Let $q$ be the index for individuals and $i$ be the index for the mode. Let $h_{q j}$ be the latent utility acquired by individual $q$ for choosing travel mode $i[11]$ :

$$
h_{q i}=\beta x_{q i}+\varepsilon_{q i},
$$

where $x_{q i}$ is the column vector of exogenous variables specified to mode $i$, and $\beta$ is the corresponding column vector of parameters to be estimated. $\varepsilon_{q i}$ represents an idiosyncratic error term [2]. Assume that $\varepsilon_{q i}$ values are identically and independently extreme values distributed with the location parameter of zero across alternative $i$ and individual $q[2]$. According to utility theory, individual $q$ selects alternative $i$ if and only if the following condition holds [11]:

$$
h_{q i}>\max _{j \neq i} h_{q i} \text {. }
$$

Let $r_{q i}$ be a dummy variable; $r_{q i}=1$ if the $i$ th mode is chosen by the $q$ th individual; $r_{q i}=0$ otherwise. Define [11] as in the following:

$$
v_{q i}=\left\{\max _{j \neq i} h_{q j}\right\}-\varepsilon_{q i} .
$$

By combining Eqs. (1) and (2):

$$
\beta x_{q i}+\varepsilon_{i}>\max _{j \neq i} h_{q j}
$$

Eq. (4) can be rewritten as follows:

$$
\beta x_{q i}>\max _{j \neq i} h_{q j}-\varepsilon_{q i} .
$$

Therefore, $r_{q i}=1$ if and only if $\beta x_{q i}>v_{q i}$.

The implied marginal distribution of $v_{q i}$ can be obtained through Eq. (3) and the distribution assumption on $\varepsilon_{q i}$ as follows [11]:

$$
\begin{aligned}
& F_{i}\left(\beta x_{q i}\right)=\operatorname{Pr}\left(v_{q i}<\beta X_{q i}\right)=\frac{\exp \left(\beta x_{q i}\right)}{\sum_{j} \exp \left(\beta x_{q j}\right)}, \\
& j=1,2, \ldots, J .
\end{aligned}
$$

The ordered logit formulation was used for the number of commute stops [1]. Let $s_{q i}^{*}$ represent the stop-making propensity of the $q$ th individual that uses mode $i . s_{q i}$ is the number of non-work stops depending on mode choice $i . s_{q i}$ is observed only for the chosen mode $i$ in the sample [1]. Then, in the usual ordered response structure, we may write the following [1]:

$$
s_{q i}^{*}=\gamma z_{q i}+\eta_{q i}, \quad s_{q i}=k, \quad \text { if } \quad \delta_{i, k-1}<s_{q i}^{*},
$$

where $z_{q i}$ is the column vector of the exogenous variable specified to mode I, and $\gamma$ is the corresponding column vector of coefficients to be estimated. $\eta_{q i}$ represents an idiosyncratic error term assumed to be a standard logistic distributed with marginal cumulative distribution function $G($.$) . \delta$ terms are the threshold bounds that horizontally partition the latent stop-making propensity and provide the relationship between the latent stop-making propensity and the observed number of stops. By convention, $\delta_{i, 0}=-\infty$ and $\delta_{i, K}=+\infty$ for each mode $i$, where $k$ is an index for number of stops $(k=1,2,3, \ldots, K)$ [1]. The probability of individual $q$ choosing mode $i$ and making $k$ commute stops is written as follows:

$$
\begin{aligned}
\operatorname{Pr}\left[r_{q i}=\right. & \left.1, s_{q i}=k\right]=\operatorname{Pr}\left[v_{q i}<\beta x_{q i}\right. \\
& \left.\delta_{i, k-1}-\gamma z_{q i}<\eta_{q i}<\delta_{i, k}-\gamma z_{q i}\right] \\
\operatorname{Pr}\left[r_{q i}=\right. & \left.1, s_{q i}=k\right]=\operatorname{Pr}\left[v_{q i}<\beta x_{q i}, \eta_{q i}<\delta_{i, k}-\gamma z_{q i}\right] \\
& -\operatorname{Pr}\left[v_{q i}<\beta x_{q i}, \eta_{q i}<\delta_{i, k-1}-\gamma z_{q i}\right] .
\end{aligned}
$$

To obtain this probability function, we need a bivariate cumulative distribution function between error terms of the two models. Therefore, copula functions were used. An $m$-copula can be defined as $m$-dimensional CDF whose support is contained in $[0,1]$ and whose one-dimensional marginal is uniform on $[0,1][12]$ : 
Table 1. Some copula characteristics.

\begin{tabular}{lcc}
\hline Copula & $\boldsymbol{C}\left(\boldsymbol{u}_{\mathbf{1}}, \boldsymbol{u}_{2}\right)$ & $\begin{array}{c}\text { Dependence } \\
\text { parameter range }\end{array}$ \\
\hline Product & $u_{1}, u_{2}$ & - \\
FGM & $u_{1} u_{2}\left(1+\theta\left(1-u_{1}\right)\left(1-u_{2}\right)\right)$ & {$[-1,1]$} \\
Gaussian & $\Phi_{\mathrm{G}}\left(\Phi^{-1}\left(u_{1}\right), \Phi^{-1}\left(u_{2}\right) ; \theta\right)$ & $(-1,1)$ \\
Clayton & $\left(u_{1}^{-\theta}+u_{2}^{-\theta}-1\right)^{-\frac{1}{\theta}}$ & $(0, \infty)$ \\
Frank & $-\theta^{-1} \log \left\{1+\frac{\left(e^{-\theta u_{1}}-1\right)\left(e^{-\theta u_{2}}-1\right)}{e^{-\theta}-1}\right\}$ & $(-\infty, \infty)$ \\
Gumbel & $\exp \left(-\left(\tilde{u}_{1}^{\theta}+\tilde{u}_{2}^{\theta}\right)^{1 / \theta}\right.$ & {$[1, \infty)$} \\
AMH & $u_{1} u_{2}\left(1-\theta\left(1-u_{1}\right)\left(1-u_{2}\right)\right)^{-1}$ & {$[-1,1]$} \\
\hline
\end{tabular}

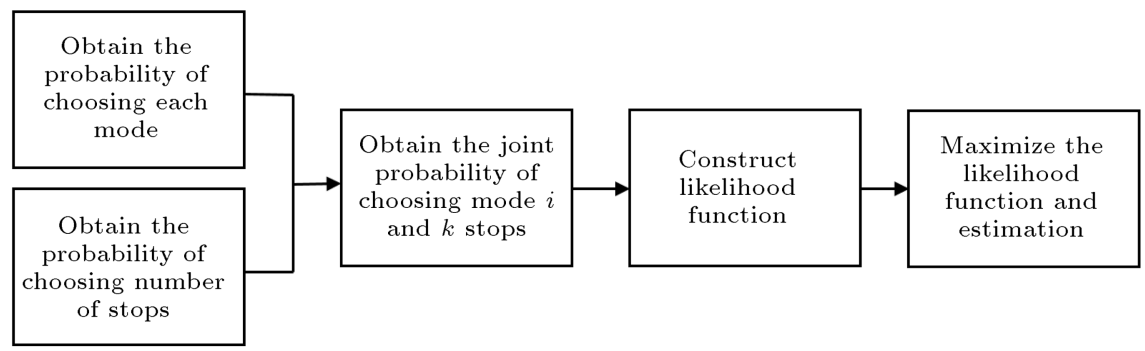

Figure 1. flowchart of methodology.

$$
\begin{aligned}
F\left(x_{1}, \ldots, x_{m}\right) & =F\left(F_{1}^{-1}\left(u_{1}\right), \ldots, F_{m}^{-1}\left(u_{m}\right)\right) \\
& =\operatorname{Pr}\left[U_{1} \leq u_{1}, \ldots, U_{m} \leq u_{m}\right] \\
& =C\left(u_{1}, \ldots, u_{m} ; \theta\right),
\end{aligned}
$$

where $\theta$ is the parameter of copula called the dependence parameter, which measures the dependence between the marginals [12].

Eq. (8) can be rewritten using copula as follows:

$$
\begin{gathered}
\operatorname{Pr}\left[r_{q i}=1, s_{q i}=k\right]=C_{\theta}\left(u_{q i 1}, u_{q i, k, 2}\right) \\
-C_{\theta}\left(u_{q i 1}, u_{q i, k-1,2}\right),
\end{gathered}
$$

where dependence parameter $(\theta)$ shows the correlation between $v_{q i}$ and $\eta_{q i}$. According to Eq. (3), the correlation between $\varepsilon_{q i}$ and $\eta_{q i}$ has an inverse sign.

Table 1 shows characteristics of some copulas [12]. For more information, see [12-14].

\subsection{Estimation procedure}

Let $1[$.$] be an indicator function taking the value$ of unity if the expression in parenthesis is true, and 0 otherwise. Also, the following dummy variable is defined as follows [1]:

$$
M_{q i k}=1\left[r_{q i}=1\right] * 1\left[s_{q i}=k\right] .
$$

The log-likelihood function for the estimation of parameters in the model takes the following form [1]:

$$
\log L=\sum_{q=1}^{Q}\left(\sum_{i=1}^{I} \sum_{k=1}^{K} M_{q i k} \log \left[\operatorname{Pr}\left(r_{q i}=1, s_{q i}=k\right)\right]\right)
$$

All parameters in the model are consistently estimated by maximizing the log-likelihood function. The parameters estimated in the joint model are $(k-1) \delta_{i, k}$, $\beta$ and $\gamma$ vectors, and dependence parameters of the best fitted copula. Maximization task is accomplished using R-studio programming. To do so, numerical methods are used to maximize log-likelihood function. Through an iterative process, convergence of answers could be achieved. Figure 1 shows the flowchart of the methodology.

\section{Data source}

The source of data used in this study is derived from the origin-destination travel data of Shiraz-Iran conducted in 1997 by Sharif University of Technology, Iran for Transportation Studies and Research (ITSR). The survey collected data from 51212 peoples aged 6 years and older. The sample used in this paper includes 1029 individuals.

Work trip chains should have at least one nonwork stop during the commute. Consider a situation where an individual has a trip from home toward work and coming back home. If an individual has at least one work trip and has one or more non-work stops, this set of trips is considered as the work trip chain. Also, the educational trip is considered as the work trip. An individual may use a variety of vehicles in his or her work trip chain. In this study, the mode used for the final leg to work is used as the work trip chain mode [1].

Five different modes were selected for the MNL 
model. These modes are private vehicle, taxi, bus, motorcycle, and other. Table 2 shows commute modes' frequency. Frequency of number of stops is presented in Table 3. Table 4 introduces exogenous variables and Table 5 shows the distribution of data by the commute mode and by number of stops for exogenous variables.

Table 2. Commute mode frequency.

\begin{tabular}{ccc}
\hline Mode & Frequency & $\begin{array}{c}\text { Frequency } \\
\text { percentage }\end{array}$ \\
\hline Private vehicle & 297 & 28.86 \\
Taxi & 281 & 27.31 \\
Bus & 302 & 29.35 \\
Motorcycle & 75 & 7.29 \\
Other & 74 & 7.19 \\
Total & 1029 & 100 \\
\hline
\end{tabular}

Table 3. Stops number frequency.

\begin{tabular}{ccc}
\hline Number of stops & Frequency & $\begin{array}{c}\text { Frequency } \\
\text { percentage }\end{array}$ \\
\hline 1 & 776 & 75.41 \\
2 & 177 & 17.20 \\
More than 2 & 76 & 7.39 \\
Total & 1029 & 100 \\
\hline
\end{tabular}

\section{Results}

Modeling is accomplished with our prior knowledge about the relationship between dependent and independent variables. An appropriate model is a model that has the biggest log-likelihood and has logical statistically significant coefficients. To investigate the matter, different copulas are examined.

In MNL model, the private vehicle is considered as the base mode and has zero utility [1]. Utility coefficients of other modes are estimated comparatively. Age, job, and life cycle group of variables have one dummy variable as the base variable. Table 6 shows the general information about modeling with different copulas.

The best fitted model is obtained by Frank copula that has a log-likelihood value of -1849.210 , as compared to -1853.150 for product (independent) copula. Table 7 shows the joint modeling results with Frank copula.

\subsection{Mode choice results}

The coefficients of the socio-demographic variables are presented favorably as expected. For example, for individuals with the driving license, a private vehicle is practically more advantageous than a taxi, bus, motorcycle, and others are. Increasing the number

Table 4. Exogenous variables.

\begin{tabular}{|c|c|c|c|}
\hline Information & Variables & Definition & $\begin{array}{l}\text { Frequency } \\
\text { percentage }\end{array}$ \\
\hline \multirow{4}{*}{ Age } & Age $6-18$ & $=1$ if age is between 6 to $18,=0$ otherwise & 6.61 \\
\hline & Age $19-30$ & $=1$ if age is between 19 to $30,=0$ otherwise & 48.98 \\
\hline & Age $31-41$ & $=1$ if age is between 31 to $41,=0$ otherwise & 22.25 \\
\hline & Age $>41$ & $=1$ if age is over than $41,=0$ otherwise & 22.16 \\
\hline Sex & Sex & $=1$ for males, $0=$ for females & 75.90 \\
\hline \multirow{4}{*}{ Job } & ADM.JOB & $=1$ if individual has an administrative job, $=0$ otherwise & 24.49 \\
\hline & SERV.JOB & $=1$ if individual has a service job, $=0$ otherwise & 30.90 \\
\hline & EDU.JOB & $=1$ if individual has an educational job, $=0$ otherwise & 36.93 \\
\hline & Other & $=1$ if individual has another job, $=0$ otherwise & 7.68 \\
\hline Driving license & $\mathrm{DL}$ & $=1$ if individual has a driving license, $0=$ otherwise & 56.46 \\
\hline $\begin{array}{c}\text { Number of } \\
\text { vehicle }\end{array}$ & NVEH & Number of vehicle & - \\
\hline Household size & HHSZ & Household size & - \\
\hline \multirow{5}{*}{ Lifecycle* $^{*}$} & LC1 & $=1$ if individual belongs to family in life cycle $1,=0$ otherwise & 10.88 \\
\hline & $\mathrm{LC} 2$ & $=1$ if individual belongs to family in life cycle $2,=0$ otherwise & 7.00 \\
\hline & LC3 & $=1$ if individual belongs to family in life cycle $3,=0$ otherwise & 23.72 \\
\hline & $\mathrm{LC} 4$ & $=1$ if individual belongs to family in life cycle $4,=0$ otherwise & 30.22 \\
\hline & LC5 & $=1$ if individual belongs to family in life cycle $5,=0$ otherwise & 28.18 \\
\hline
\end{tabular}

* a) Families with the oldest child under 6 years;

b) Families with the oldest child between 6 and 11 years;

c) Families with the oldest child between 12 and 18 years;

d) Families with at least one child over 18 and youngest child under 18;

e) Other types of families $[16,17]$. 
Table 5. Distributions by commute mode and by number of stops for exogenous variables.

\begin{tabular}{|c|c|c|c|c|c|c|c|c|}
\hline \multirow[b]{3}{*}{ Variable } & \multicolumn{8}{|c|}{ Model } \\
\hline & \multicolumn{3}{|c|}{ OL } & \multicolumn{5}{|c|}{ MNL } \\
\hline & 1 stop & 2 stop & $\begin{array}{l}\text { More than } \\
2 \text { stops }\end{array}$ & $\begin{array}{l}\text { Private } \\
\text { vehicle }\end{array}$ & Taxi & Bus & $\begin{array}{c}\text { Motor } \\
\text { cycle }\end{array}$ & Others \\
\hline Age 6-18 & 91.18 & 7.35 & 1.47 & 5.88 & 47.06 & 41.18 & 2.94 & 2.94 \\
\hline Age 19-30 & 75.20 & 16.67 & 8.13 & 13.29 & 32.74 & 42.66 & 6.75 & 4.56 \\
\hline Age $31-41$ & 68.56 & 21.83 & 9.61 & 41.05 & 22.27 & 13.97 & 10.48 & 12.23 \\
\hline Age $>41$ & 78.07 & 16.67 & 5.26 & 57.89 & 15.79 & 10.53 & 6.58 & 9.21 \\
\hline Male & 74.39 & 18.82 & 6.79 & 34.70 & 25.86 & 20.61 & 9.48 & 9.35 \\
\hline Female & 78.63 & 12.10 & 9.27 & 10.48 & 33.06 & 55.65 & 0.4 & 0.4 \\
\hline ADM.JOB & 70.63 & 19.84 & 9.53 & 36.51 & 23.81 & 22.22 & 7.94 & 9.52 \\
\hline SERV.JOB & 77.04 & 17.92 & 5.03 & 44.97 & 22.64 & 5.35 & 14.15 & 12.89 \\
\hline EDU.JOB & 76.58 & 15.26 & 8.16 & 4.74 & 36.32 & 55.53 & 2.37 & 1.05 \\
\hline Other & 78.48 & 15.19 & 6.33 & 55.69 & 17.72 & 18.99 & 1.27 & 6.33 \\
\hline DL & 74.01 & 18.59 & 7.40 & 47.67 & 20.31 & 12.39 & 9.47 & 10.15 \\
\hline No DL & 77.23 & 15.40 & 7.37 & 4.46 & 37.05 & 50.67 & 4.46 & 3.35 \\
\hline LC1 & 63.39 & 25.89 & 10.72 & 29.46 & 21.43 & 16.07 & 16.07 & 16.96 \\
\hline $\mathrm{LC} 2$ & 75.00 & 13.89 & 11.11 & 45.83 & 22.22 & 18.06 & 8.33 & 5.56 \\
\hline LC3 & 77.05 & 14.34 & 8.61 & 37.29 & 22.54 & 21.72 & 9.43 & 9.02 \\
\hline $\mathrm{LC} 4$ & 77.49 & 18.65 & 3.86 & 35.04 & 25.58 & 21.54 & 6.43 & 7.41 \\
\hline LC5 & 76.55 & 15.52 & 7.93 & 10.69 & 33.45 & 51.03 & 2.76 & 2.07 \\
\hline
\end{tabular}

Table 6. General information about modeling with different copulas.

\begin{tabular}{|c|c|c|c|c|c|c|c|c|}
\hline \multirow{2}{*}{ Copula } & \multirow{2}{*}{$\begin{array}{l}\text { Acceptable } \\
\text { range for } \theta\end{array}$} & \multicolumn{5}{|c|}{ Dependent parameters } & \multirow{2}{*}{$\begin{array}{c}\text { Acceptable } \\
\text { models }\end{array}$} & \multirow{2}{*}{$\begin{array}{c}\text { Log- } \\
\text { likelihood }\end{array}$} \\
\hline & & Private vehicle & Taxi & Bus & Motor & Others & & \\
\hline Frank & $(-\infty, \infty)$ & 1.236 & 0.600 & 2.031 & 1.422 & 1.661 & $\sqrt{ }$ & -1849.21 \\
\hline Product & - & - & - & - & - & - & $\sqrt{ }$ & -1853.15 \\
\hline Gumbel & {$[1, \infty)$} & 1.123 & 1.030 & 1.208 & 1.163 & 1.226 & $\sqrt{ }$ & -1849.34 \\
\hline Gaussian & $(-1,1)$ & -2.448 & -1.312 & 8.376 & 5.456 & -5.094 & $x$ & - \\
\hline FGM & {$[-1,1]$} & 1.516 & 0.753 & 1.396 & 0.985 & 1.276 & $x$ & - \\
\hline $\mathrm{AMH}$ & {$[-1,1]$} & 1.334 & 0.575 & 1.232 & 0.860 & 1.143 & $x$ & - \\
\hline
\end{tabular}

of private vehicle ownership causes more favorability of private vehicle than other modes. As individual age increases, public transport (bus and taxi) loses its utility, and private vehicle utility increases instead. Further, motorcycle and others have more practical advantage for men rather than women.

\subsection{Number of non-work stops results}

Similar to the mode choice, numbers of non-work results are sufficient as expected. Individuals in 6-18 years old groups have a lower propensity for more nonwork stops. Also, men have a higher propensity for more non-work stops rather than women. People in life cycle 1 have a higher stop-making propensity than other life cycle groups. Results show that driving li- cense, the number of vehicle ownership, and household size do not have any effects on the number of non-work stops.

\subsection{Correlation parameters}

Dependence parameters of each mode are significantly different from zero, indicating a positive correlation among common unobserved factors related to both mode choice and the number of non-work stops, specifically between error terms $v_{q i}$ and $\eta_{q i}$. The positive dependence parameters indicate a negative correlation between utility error term $\left(\varepsilon_{q i}\right)$ and propensity error term $\left(\eta_{q i}\right)$. These negative correlations are interpretable. For example, a workplace in the central business district is an unobserved factor that increases stop 
Table 7. Joint modeling results with frank copula.

\begin{tabular}{|c|c|c|c|c|c|c|}
\hline \multirow{2}{*}{ Variable } & \multicolumn{5}{|c|}{ MNL } & \multirow{2}{*}{ OL } \\
\hline & Private vehicle & Taxi & Bus & Motor cycle & Others & \\
\hline \multicolumn{7}{|l|}{ Dependence parameters } \\
\hline Private vehicle & - & - & - & - & - & $1.237(1.216)$ \\
\hline Taxi & - & - & - & - & - & $0.600(0.706)$ \\
\hline Bus & - & - & - & - & - & $2.031(2.075)$ \\
\hline Motorcycle & - & - & - & - & - & $1.423(1.551)$ \\
\hline Other & - & - & - & - & - & $1.662(1.652)$ \\
\hline Constants & - & $\begin{array}{c}2.419 \\
(5.145)\end{array}$ & $\begin{array}{c}1.485 \\
(3.132)\end{array}$ & $\begin{array}{c}-2.530 \\
(-2.301)\end{array}$ & $\begin{array}{c}-0.963 \\
(-0.890)\end{array}$ & $\begin{array}{c}-1.807 \\
(-4.300)\end{array}$ \\
\hline Age 6-18 (base) & - & - & - & - & - & - \\
\hline Age $19-30$ & - & - & $\begin{array}{c}0.481 \\
(2.095)\end{array}$ & $\begin{array}{c}1.006 \\
(3.316)\end{array}$ & - & $\begin{array}{c}1.365 \\
(3.052)\end{array}$ \\
\hline Age $31-41$ & - & $\begin{array}{c}-0.611 \\
(-2.406)\end{array}$ & - & - & - & $\begin{array}{c}1.800 \\
(3.668)\end{array}$ \\
\hline Age $>41$ & - & $\begin{array}{c}-1.130 \\
(-3.982)\end{array}$ & $\begin{array}{c}-0.432 \\
(-1.368)\end{array}$ & - & $\begin{array}{c}-0.638 \\
(-2.162)\end{array}$ & $\begin{array}{c}1.376 \\
(2.721)\end{array}$ \\
\hline Sex & - & - & $\begin{array}{c}-0.223 \\
(-1.274)\end{array}$ & $\begin{array}{c}2.595 \\
(2.526)\end{array}$ & $\begin{array}{c}2.422 \\
(2.361)\end{array}$ & $\begin{array}{c}0.355 \\
(1.746)\end{array}$ \\
\hline SERV.JOB (base) & - & - & - & - & - & - \\
\hline ADM.JOB & - & - & $\begin{array}{c}1.514 \\
(4.986)\end{array}$ & - & - & $\begin{array}{c}0.417 \\
(2.269)\end{array}$ \\
\hline EDU.JOB & - & $\begin{array}{c}0.743 \\
(2.343)\end{array}$ & $\begin{array}{c}2.424 \\
(6.462)\end{array}$ & - & $\begin{array}{c}-1.022 \\
(-1.703)\end{array}$ & $\begin{array}{c}0.587 \\
(2.366)\end{array}$ \\
\hline Others & - & $\begin{array}{c}-0.441 \\
(-1.224)\end{array}$ & $\begin{array}{c}1.037 \\
(2.368)\end{array}$ & $\begin{array}{c}-2.087 \\
(-2.035)\end{array}$ & - & - \\
\hline DL & - & $\begin{array}{c}-1.879 \\
(-6.117)\end{array}$ & $\begin{array}{c}-2.339 \\
(-7.373)\end{array}$ & $\begin{array}{c}-1.712 \\
(-4.648)\end{array}$ & $\begin{array}{c}-1.432 \\
(-3.476)\end{array}$ & - \\
\hline NVEH & - & $\begin{array}{c}-1.553 \\
(-7.651)\end{array}$ & $\begin{array}{c}-1.479 \\
(-7.006)\end{array}$ & $\begin{array}{c}-0.358 \\
(-1.480)\end{array}$ & $\begin{array}{c}-1.191 \\
(-4.467)\end{array}$ & - \\
\hline HHSZ & - & $\begin{array}{l}-0.132 \\
(2.519)\end{array}$ & - & - & - & - \\
\hline $\mathrm{LC} 1$ & - & $\begin{array}{c}-0.424 \\
(-1.259)\end{array}$ & $\begin{array}{c}-0.736 \\
(-2.051)\end{array}$ & $\begin{array}{c}0.588 \\
(1.676)\end{array}$ & - & $\begin{array}{c}0.622 \\
(2.837)\end{array}$ \\
\hline $\mathrm{LC} 2$ & - & - & - & - & $\begin{array}{c}-1.090 \\
(-1.999)\end{array}$ & - \\
\hline LC3 & - & - & - & $\begin{array}{c}0.554 \\
(1.723)\end{array}$ & - & - \\
\hline LC4 (base) & - & - & - & - & - & - \\
\hline LC5 & - & $\begin{array}{c}0.410 \\
(1.621) \\
\end{array}$ & - & - & - & - \\
\hline Threshold 1-2 stops & - & - & - & - & - & $\begin{array}{c}0.999 \\
(4.928)\end{array}$ \\
\hline Threshold 2-3 stops & - & - & - & - & - & $\begin{array}{c}2.414 \\
(10.456)\end{array}$ \\
\hline
\end{tabular}


Table 8. Aggregate elasticity for some dummy and ordinal variables.

\begin{tabular}{ccccccc}
\hline \multirow{2}{*}{ Variable } & \multirow{2}{*}{ Type of change } & \multicolumn{5}{c}{ MNL } \\
\cline { 3 - 6 } & & Private vehicle & Taxi & Bus & Motor cycle & Others \\
\hline Sex & From 1 to 0 & 10.553 & 2.024 & 8.487 & -12.557 & -11.722 \\
DL & From 1 to 0 & -36.285 & 4.007 & 16.931 & 6.604 & 0.767 \\
NVEH & Added one unit & 21.132 & -10.519 & -5.629 & -3.326 & -5.462 \\
HHSZ & Added one unit & -0.041 & 2.803 & -2.260 & -0.411 & -0.442 \\
\hline
\end{tabular}

propensity due to the presence of many opportunities in these districts and private vehicle utility decreases, because there is condensed traffic in these districts. It can be used to interpret a negative correlation among private utility and stop-making propensity error terms.

The statistical significance of dependence parameter is in accordance with the expectations and previous research results. This point can be used to validate the model.

\subsection{Elasticity}

Elasticity is a concept that can be employed for continuous variables. There is no continuous variable in the exogenous variable set. To determine the aggregate elasticity for dummy and ordinal variable, the following measure has been taken [15]:

- For dummy variables, we change one values to zero and zero values to one. Then, the absolute shifts in the expected share are summed up;

- For ordinal variables, we increase variables by one and compute expected shifts.

This elasticity is disaggregating. To determine aggregate elasticity, we use [11]:

$$
E_{x i}^{\bar{P}(i)}=\frac{\sum_{n=1}^{N} P_{n}(i)^{*} E_{x_{i n}}^{P_{n}}(i)}{\sum_{n=1}^{N} P_{n}(i)}, \quad(n=1, \ldots, N),
$$

where $E_{x_{i n}}^{P_{n}^{(i)}}$ is the disaggregate elasticity for $x_{i}$ variable, $i$ is the mode choice, and $P_{n}(i)$ is the probability of mode $i$ chosen by individual $n$.

Table 8 shows the aggregate elasticity for some dummy and ordinal variables.

\section{Conclusion}

In this study, the interaction between commute mode choice and the number of non-work stops was examined in the copula-based joint model framework. The existing common or related observed and unobserved factors between the two models were captured by joint modeling. The copula function was used to combine unobserved factors of models and approved results of these correlations through estimating significant parameters statistically for copula dependence. This model can be used in two ways: to predict future travel demands of society and have an appropriate planning to respond; to use the results to set policies for the current situation so as to reduce traffic congestion. Those factors that increase the probability of using public transport and having more non-work stops should be supported. The important point is that these results, while validated, are viable for Shiraz only, not for anywhere else.

\section{References}

1. Portoghese, A., Bhat, C.R., and Eluru, N. "A copulabased joint model of commute mode choice and number of non-work stops during the commute", Transportation Research Part B, 38(3), pp. 337-362 (2011).

2. Bhat, C.R. "Work travel mode choice and number of non-work commute stops", Transportation Research Part B, 31(1), pp. 41-54 (1997).

3. Cao, X., Mokhtarian, P.L., and Handy, S.L. "Differentiating the influence of accessibility, attitudes, and demographics on stop participation and frequency during the evening commute", Environment and Planning B, 35(3), pp. 431-442 (2008).

4. Chu, Y.L. "Empirical analysis of commute stopmaking behavior", Transportation Research Record: Journal of the Transportation Research Board, 1831, pp. 106-113 (2003).

5. Lizana, P., Arellana, J., Ortuzar, J.D., and Rizzi, L.I. "Modeling mode and time-of-day choice with joint RP and SC data", International Choice Modelling Conference, Sydney, Australia (2013).

6. Ye, X., Pendyala, R.M., and Gottardi, G. "An exploration of the relationship between mode choice and complexity of trip chaining patterns", Transportation Research Part B, 41(1), pp. 96-113 (2007).

7. Bhat, C.R. and Sardesai, R. "The impact of stopmaking and travel time reliability on commute mode choice" Transportation Research Part B, 40(9), pp. 709-730 (2006).

8. Strathman, J.G., Dueker, K.J., and Davis, J.S. "Effects of household structure and selected travel characteristics on trip chaining", Transportation, 21(1), pp. 23-45 (1994). 
9. Hensher, D.A. and Reyes, A.J. "Trip chaining as a barrier to the propensity to use public transport" Transportation, 27(4), pp. 341-361 (2000).

10. Damm, D. "Interdependencies in activity behavior", Transportation Research Record: Journal of the Transportation Research Board, 750, pp. 33-40 (1980).

11. Ben-Akiva, M.E. and Lerman, S., Discrete Choice Analysis: Theory and Applications to Travel Demand, MIT Press (1985).

12. Trivedi, P.K. and Zimmer, D.M., Copula Modeling: an Introduction for Practitioners, Now Publishers Inc (2007).

13. Piotr, J., Durante, F., and Hardle, W.K., Copula in Mathematical and Quantitative Finance, Springer (2012).

14. Nelsen, R.B., An Introduction to Copulas (2nd Ed.), Springer (2006).

15. Daly, A. and Hess, S. "Simple approaches for random utility modeling with panel data", TRB Annual Meeting, Washington DC (2013).

16. Owen, D., Yilin, S., and Octavious, S.Y. "Designing low carbon cities with a family lifecycle in mind: Where should our focus be?" TRB Annual Meeting, Washington DC (2014).
17. Sun, Y., Huang, Z., and Kitamura, R. "Travel behavior, household in the same life cycle stage", Built Environment, ICTE, pp. 1-6 (2011).

\section{Biographies}

Arash Rasaizadi obtained his BSc degree in Civil Engineering from Shahid Bahonar University of Kerman, Kerman, Iran in 2013; he also received his MSc degree in Transportation Engineering from Sharif University of Technology, Tehran, Iran in 2015. He is currently a $\mathrm{PhD}$ student in the Transportation Planning in Tarbiat Modares, Tehran, Iran. His research interests include forecast and management of urban travel demand, transportation behavior, and urban transportation planning.

Mohammad Kermanshah received his BS degree in 1974 from Shiraz University, Iran, his MS degree from South Dakota School of Mines \& Technology in USA in 1978, and his PhD degree from the University of Davis, California, USA in 1984. He is now a Professor of Civil Engineering at Sharif University of Technology, Tehran, Iran. His research interests include transportation modeling, urban transportation planning, and transportation demand management. 